\begin{tabular}{|c|c|c|c|c|}
\hline $\begin{array}{c}\text { Jurnal Penelitian \& } \\
\text { PPM }\end{array}$ & ISSN: 2442-448X & Vol 5, No: 1 & Hal: 1 - 110 & April 2018 \\
\hline
\end{tabular}

\title{
Dimensi Kesehatan Mental Pada Pengungsi Akibat Bencana
}

\author{
Oleh: \\ Meilanny Budiarti S., Moch. Zaenuddin, Hetty Krisnani, Rizky Adrian Assidiq \\ 1. Dosen IImu Kesejahteraan Sosial, Fakultas IImu Sosial Dan IImu Politik, Universitas Padjadjaran \\ 2. Dosen IImu Kesejahteraan Sosial, Fakultas IImu Sosial Dan IImu Politik, Universitas Padjadjaran \\ 3. Dosen IImu Kesejahteraan Sosial, Fakultas IImu Sosial Dan IImu Politik, Universitas Padjadjaran \\ Email: \\ meilannybudiarti13@gmail.com, zaenuddin59@gmail.com, hettykrisnani@yahoo.com, rizkyadrian@gmail.com
}

\begin{abstract}
ABSTRAK
Bencana adalah kejadian yang sangat ditakui oleh semua manusia di manapun, dengan terjadinya bencana semua orang dalam wilayah bencana akan mengalami kehancuran, kehilangan dan kesengsaraan. Bukan hanya kehilangan harta benda, melainkan juga kehilangan nyawa dan sanak saudara yang terpisah dalam upaya menyelamatkan diri ataupun karena terbawa oleh situasi bencana yang menghancur leburkan dan memporak porandakan tempat tinggal. Dengan terjadinya bencana, pengungsi menjadi hal utama yang harus diperhatikan, mulai dari pemenuhan kebutuhan pangan, sandang dan papan mereka agar dapat terus melanjutkan kehidupan mereka. Hal penting lainnya yang harus diperhatikan adalah kondisi kesehatan mental para pengungsi yang sangat mungkin mengalami gangguan kesehatan mental akibat bencana yang terjadi. Dalam artikel ini dibahan dimensi-dimensi yang dapat digunakan untuk menditeksi kondisi kesehatan mental bagi para pengungsi khususnya.
\end{abstract}

Kata kunci : bencana, pengungsi, gangguan kesehatan mental

\begin{abstract}
Disaster is an event that every human being can recognize everywhere, with the disaster of all people in the disaster area going through destruction, loss and misery. Not only the loss of property, but also the loss of life and relatives are separated in an effort to save themselves or because carried away by a disaster situation that destroyed the melting and destructive dwelling. With the occurrence of disasters, refugees become the main thing to be considered, ranging from the fulfillment of food needs, clothing and their boards in order to continue their lives. Another important thing to note is the mental health condition of refugees who are very likely to experience mental health disorders due to the disaster that occurred. In this article, there are dimensions that can be used to detect mental health conditions for the refugees in particular.
\end{abstract}

Keywords: disaster, refugees, mental health disorders

\section{Pendahuluan}

Bencana adalah salah satu hal yang paling ditakuti oleh dunia, baik itu oleh negara miskin, negara berkembang, maupun oleh negara miskin. Bencana dapat terjadi karena bencana alam seperti: bencana tsunami, gempa, ataupun banjir. Maupun bencana akibat dari perbuatan tangan manusia seperti: terjadinya perang, krisis ekonomi di dalam negara, atau karena konflik internal suatu negara. Semua jenis bencana sangat ditakuti karena mempunyai dampak buruk yang menyebar luas, baik pada saat bencana itu terjadi maupun setelah kejadian bencana berlalu.
Saat terjadi bencana, tentunya terjadi banyak kerusakan materil seperti rusaknya rumah tinggal dan gedung-gedung pemerintahan, rusaknya infrastruktur jalan dan rumah sakit, serta berbagai macam kerusakan lainnya. Begitupun setelah bencana berlalu, meninggalkan dampak buruk bagi masyarakatnya seperti banyaknya pengungsi yang mengalami kerugian baik secara moril maupun materil, dan bahkan hingga terganggunya kesehatan mental mereka.

Berbicara mengenai pengungsi, dapat dimaknai berdasarkan banyak perspektif. Salah satunya adalah pengertian pengungsi yang dikeluarkan oleh konfrensi PBB tahun 
1951. Bahwa yang dimaksud dengan pengungsi adalah:

Memiliki rasa takut yang beralasan akan adanya penganiayaan yang berdasarkan atas ras, agama, kebangsaan, keanggotaan pada kelompok sosial tertentu atau pandangan politik, yang berada di luar negara asalnya, dan tidak dapat atau karena rasa takutnya, tidak bersedia menerima perlindungan dari negaranya (PBB, 1951).

Sejalan dengan pendapat dari konferensi PBB tahun 1951, Jesuit Refugee Service Indonesia (JRS) sebagai organisasi yang bergerak di bidang perlindungan pengungsi mengungkapkan bahwa JRS menggunakan definisi "pengungsi de facto" yang mencakup:

"semua orang yang dianiaya berdasarkan ras, agama, keanggotaan dalam kelompok sosial atau politik"; dan "mereka yang menjadi korban dari konflik bersenjata, kebijakan ekonomi yang keliru atau korban bencana alam; serta, demi “alasan kemanusiaan”, termasuk juga dalam definisi ini adalah mereka yang disebut pengungsi internal, yakni warga negara yang "terpaksa meninggalkan kampung halamannya karena alasan kekerasan yang sama dengan pengungsi pada umumnya namun mereka tidak melintasi batas-batas negara" (Jesuit Refugee Service Indonesia, 2013).

Pasca terjadinya sebuah bencana kondisi para pengungsi sangat rentan untuk mengalami gangguan kesehatan mental bahkan hal ini menjadi hal yang paling rentan dihadapi oleh para pengungsi karena tekanan yang besar akibat kehilangan harta dan keluarga serta keputusasaan karena tidak tahu bagaimana cara melanjutkan kehidupannya. Kesehatan mental yang terganggu terus menerus akan mengakibatkan penyakit mental lainnya seperti anxiety, depresi hingga mengidap PTSD (Pos Traumatic Stress Disorder).

Sejalan dengan yang diungkapkan oleh Bukfa \& Barlow (2006: 1) dalam Kusumo (2009) bahwa seseorang yang mengalami kondisi sangat ekstrem seperti tertimpa bencana, sehingga mereka tidak dapat menerima kenyataan yang dialaminya, mungkin mereka menderita Post-Traumatic Stress Disorder (PTSD), sebuah kondisi nyata dan melemahkan kesehatan. Mereka akan merasa sangat gelisah, cemas, takut dan bahkan mengalami kesedihan yang mendalam.

Untuk dapat mengenali terganggu atau tidaknya kondisi kesehatan mental seseorang terlebih bagi para pengungsi akibat bencana, maka dapat dikenali dengan memahami dimensi-dimensi kesehtan mental pada yang bersangkutan.

\section{Tinjauan Pustaka}

Dimensi Kesehatan Mental Maslow dan Mittlemenn (dalam Notosoedirjo \& Latipun, 2005) menguraikan pandangannya mengenai prinsip-prinsip kesehatan mental, yang menyebutnya dengan manifestation of psychological health. Maslow menyebut kondisi yang sehat secara psikologis itu dengan istilah self actualization sekaligus sebagai puncak kebutuhan dari teori hierarki kebutuhan yang disusunya. Manifestasi mental yang sehat (secara psikologis) menurut Maslow dan Mittlemenn (dalam Notosoedirjo \& Latipun, 2005) tercermin dari kesebelas dimensi kesehatan mental berikut ini:

1. Adequate feeling of security (rasa aman yang memadai). Perasaan merasa aman dalam hubungannya dengan pekerjaan, sosial, dan keluarganya.

2. Adequate self evaluation (kemampuan menilai diri sendiri yang memadai), yang mencakup: (a) Memiliki harga diri yang memadai dan merasa ada nilai yang sebanding antara keadaan diri yang sebenarnya (potensi diri) dengan prestasinya, (b) Memiliki perasaan berguna akan diri sendiri, yaitu perasaan yang secara moral masuk 
akal, dan tidak diganggu oleh rasa bersalah yang berlebihan, dan mampu mengenal beberapa hal yang secara sosial dan personal tidak dapat diterima oleh kehendak umum yang selalu ada sepanjang kehidupan di masyarakat.

3. Adequate spontaneity and emotionality (memiliki spontanitas dan perasaan yang memadai dengan orang lain). Hal ini ditandai oleh kemampuan membentuk ikatan emosional secara kuat dan abadi, seperti hubungan persahabatan dan cinta, serta mampu untuk mengekspresikan ketidaksukaan/ketidaksetujuan tanpa kehilangan kontrol, kemampuan memahami dan membagi perasaan kepada orang lain, kemampuan menyenangi diri sendiri dan tertawa. Ketika seseorang tidak senang terhadap suatu hal pada suatu saat, maka dia harus memiliki alasan yang tepat mengapa dia tidak senang.

4. Efficient contact with reality (mempunyai kontak yang efisien dengan realitas) kontak ini sedikitnya mencakup tiga aspek yaitu dunia fisik, sosial, dan diri sendiri/internal. Hal ini ditandai oleh: (a) Tiadanya fantasi (khayalan dan angan-angan) yang berlebihan, (b) Mempunyai pandangan yang realistis dan luas terhadap dunia, yang disertai dengan kemampuan menghadapi kesulitan hidup seharihari, misalnya sakit dan kegagalan, dan (c) Kemampuan untuk merubah diri sendiri jika situasi eksternal (lingkungan) tidak dapat dimodifikasi (diubah) dan dapat bekerjasama tanpa merasa tertekan (cooperation with the inevitable)

5. Adequate bodily desires and ability to gratify them (keinginan-keinginan jasmani yang memadai dan kemampuan untuk memuaskannya). Hal ini ditandai dengan: (a) Suatu sikap yang sehat terhadap fungsi jasmani, dalam arti menerima fungsi jasmani tetapi bukan dikuasai oleh fungsi jasmani tersebut, (b) Kemampuan memperoleh kenikmatan dan kebahagiaan dari dunia fisik dalam kehidupan seperti makan, tidur, dan pulih kembali dari kelelahan,(c) Kehidupan seksual yang wajar dan keinginan yang sehat untuk memuaskannya tanpa rasa takut dan konflik, (d) Kemampuan bekerja, (e) Tidak adanya kebutuhan yang berlebihan untuk mengikuti berbagai aktivitas.

6. Adequate self knowledge (mempunyai kemampuan pengetahuan yang wajar). Termasuk di dalamnya adalah: (a) Cukup mengetahui tentang: motif, keinginan, tujuan, ambisi, hambatan, kompetensi, pembelaan, dan perasaan rendah diri, (b) Penilaian yang realistis terhadap diri sendiri baik kelebihan maupun kekurangan, (c) Mampu menilai diri secara jujur (jujur pada diri sendiri), mampu untuk menerima diri sendiri apa adanya, dan mengakui serta menerima sejumlah hasrat atau pikiran meskipun beberapa diantara hasrathasrat itu secara sosial dan personal tidak dapat diterima.

7. Integration and consistency of personality (kepribadian yang utuh dan konsisten). Ini bermakna bahwa: (a) Cukup baik perkembangan diri dan kepribadiannya, kepandaiannya, dan berminat dalam beberapa aktivitas, (b) Memiliki prinsip moral dan kata hati yang tidak terlalu berbeda dengan pandangan kelompok, (c) Mampu untuk berkonsentrasi, (d) Tidak adanya konflik-konflik besar dalam kepribadian dan tidak dissosiasi terhadap kepribadiannya.

8. Adequate of life goal (memiliki tujuan hidup yang wajar). Hal ini berarti: (a) Memiliki tujuan hidup yang sesuai dengan dirinya sendiri dan dapat dicapai, (b) Mempunyai usaha yang tekun dalam mencapai tujuan tersebut, dan (c) Tujuan itu bersifat baik untuk diri sendiri dan masyarakat. 
9. Ability to learn from experience (kemampuan belajar dari pengalaman). Kemampuan untuk belajar dari pengalaman hidupnya sendiri. Bertambahnya pengetahuan, kemahiran dan keterampilan mengerjakan sesuatu berdasarkan hasil pembelajaran dari pengalamannya. Selain itu, juga termasuk didalamnya kemampuan untuk belajar secara spontan.

10. Ability to satisfy to requirements of the group (kemampuan memuaskan tuntutan kelompok). Dalam hal ini, individu harus: (a) Dapat memenuhi tuntutan kelompok dan mampu menyesuaikan diri dengan anggota kelompok yang lain tanpa harus kehilangan identitas pribadi dan diri sendiri, (b) Dapat menerima normanorma yang berlaku dalam kelompoknya, (c) Mampu menghambat dorongan hasrat diri sendiri yang dilarang oleh kelompoknya, (d) Mau berusaha untuk memenuhi tuntutan dan harapan kelompoknya: ambisi, ketepatan, persahabatan, rasa tanggung jawab, dan kesetiaan, serta (e) Berminat untuk melakukan aktivitas atau kegiatan yang disenangi oleh kelompoknya.

11. Adequate emancipation from the group or culture (mempunyai emansipasi yang memadai dari kelompok atau budaya). Hal ini mencakup: (a) Kemampuan untuk menilai sesuatu itu baik dan yang lain adalah buruk berdasarkan penilaian diri sendiri tanpa terlalu dipengaruhi oleh kebiasaankebiasaan dan budaya serta kelompok, (b) Dalam beberapa hal bergantung pada pandangan kelompok, (c) Tidak ada kebutuhan yang berlebihan untuk membujuk (menjilat), mendorong, atau menyetujui kelompok, dan (d) Mampu menghargai perbedaan budaya.

\section{Metode}

Artikel ini disusun dengan menggunakan kajian literatur dan dokumen, yaitu literatur barupa buku-buku, makalah ataupun jenis tulisan lainnya dan juga kajian terhadap berbagai macam dokumen yang terkait dengan topik kesehatan mental pengungsi dan pencari suaka yang diangkat dalam artikel ini.

\section{Pembahasan}

Pengungsi yang kita tahu adalah korban dari bencana yang mengalami trauma dan kesehatan mentalnya terganggu. Bila dikaji berdasarkan dimensi kesehatan mental yang diungkapkan oleh Maslow dan Mittlemenn (dalam Notosoedirjo \& Latipun, 2005), maka hal yang pertama adalah terpenuhinya adequate feeling of security (rasa aman yang memadai). Pengungsi akibat terjadinya bencana alam, perang, ataupun krisis dan konflik negara harus merasakan rasa aman setelah bencana itu terjadi. Hilangnya perasaan aman akan membuat tekanan yang ada dalam diri pengungsi. Terlebih dengan terjadinya bencana, maka muncul ancaman kehilangan pekerjaan, kehidupan sosial dan keluarga pun menjadi terancam. Pemenuhan rasa aman bagi pengungsi dapat dilakukan dengan cara memberi jaminan pemenuhan kebutuhan hidup, dukungan mengenai pekerjaan, ataupun informasi mengenai bagaimana keadaan keluarganya.

Kedua adalah adequateself evaluation (kemampuan menilai diri sendiri yang memadai). Pengungsi membutuhkan perasaan bahwa mereka masih mempunyai potensi untuk bisa mengubah keadaan hidup mereka yang diakibatkan karena terjadinya bencana. Perasaan seperti ini akan mengurangi rasa bersalah dan tertekan yang dialami oleh pengungsi. Pengungsi anak-anak juga harus diberikan dorongan agar bisa membangkitkan semangat untuk mengembangkan potensi dalam diri mereka melalui kegiatan positif untuk menghilangkan trauma akibat kejadian saat bencana terjadi.

Ketiga adalah spontaneity and emotionaliti (memiliki spontanitas dan 
perasaan memadai dengan orang lain) Pengungsi saat setelah bencana itu terjadi harus memiliki ikatan emosional untuk membentuk hubungan persahabatan dan cinta, sehingga memberikan dampak positif kepada sesama pengungsi lainnya, serta mampu mengontrol perasaan negatif. Dengan demikian, tekanan dalam diri pengungsi bisa berkurang. Dalam hal ini, terkait dengan pengungsi anak-anak, maka kemampuan mereka untuk tertawa dan menyenangi apa yang ada pada diri mereka sendiri adalah hal penting.

Keempat adalah efficient contact with reality (mempunyai kontak yang efisien dengan realitas). Pengungsi juga harus terhindar dari fantasi atau berhalusinasi tentang sesuatu yang tidak sesuai dengan realita. Hal itu bisa menyebabkan pengungsi tidak bisa menerima kenyataan yang ada (fakta) yang terjadi pada dirinya, sehingga akan merasakan perasaan kecewa, merasa gagal serta tidak berharga.

Kelima adalah adequate desires and ability to grafity them (keinginan-keinginan jasmani yang memadai dan kemampuan untuk memuaskannya). Pengungsi dalam hal ini harus terpenuhi kebutuhan jasmaninya, kebutuhan untuk menikmati makan, tidur dan mampu untuk bekerja sebagai aktivitas seharihari. Hal ini akan memperkecil perbedaan yang ada pada saat sebelum dan sesudah terjadinya bencana dalam kehidupan pengungsi. Anakanak dalam hal ini juga tetap mendapatkan pendidikan walaupun sebagai pengungsi, hendaknya anak-anak tetap bisa makan dan tidur yang layak di tempat dia mengungsi.

Keenam adalah adequate self knowledge (mempunyai kemampuan positif yang wajar). Pengungsi juga harus mempunyai tujuan dan keinginan tentang kehidupan setelah bencana, hal ini membuat mereka mempunyai semangat untuk kembali memulai kehidupan dan merubah kehidupan yang ada saat sebagai pengungsi. Pengungsi juga harus menyadari dan dapat menerima keadaannya yang sekarang sedang menimpanya.

Ketujuh adalah integration and consistency of personality (kepribadian yang utuh dan konsisten) Pengungsi juga harus bisa mengembangkan diri dengan lingkungan baru di tempat pengungsian. Mampu berkonsentrasi dan punya minat yang cukup besar di dalam semua aktivitasnya, sehingga ada kemampuan untuk bisa bangkit dari dampak buruk bencana. Selain itu, kemampuan untuk mengembangkan diri juga akan mengurangi konflik dalam diri pengungsi sendiri. Hal ini terkait dengan apa yang menjadi keinginan dari pengungsi dibandingkan dengan kenyataan yang ada, yang kemungkinan besar hal ini berbeda, sehingga kemampuan dalam mengembangkan diri ini bisa menjadi jalan untuk mewujudkan keinginan para pengungsi untuk menjadi kenyataan.

Kedelapan adalah adequate of life goal (memiliki tujuan hidup yang wajar). Pengungsi baik itu dewasa dan anak-anak harus samasama mempunyai tujuan dalam hidup mereka. Tujuan hidup ini berguna agar mereka bisa menata bagaimana kehidupan mereka selanjutnya. Tujuan ini harus juga disesuaikan dengan keadaan dari pengungsi, tujuan yang terlalu berlebihan akan membuat pengungsi menjadi stress karena tidak bisa mencapai tujuannya tersebut.

Kesembilan adalah ability of learn from experience (kemampuan belajar dari pengalaman). Pengungsi harus bisa beradaptasi dan belajar dari kejadian bencana yang telah dialaminya. Kemampuan ini berguna untuk memperkuat mental para pengungsi ketika kejadian yang sama terulang di kemudian hari.

Kesepuluh adalah ability to satisfy to requirements of the group (kemampuan memuaskan tuntutan kelompok). Pengungsi harus mampu untuk beradaptasi dengan lingkungan dan kelompok baru di kehidupannya. Kemampuan beradaptasi ini akan membuat pengungsi bisa membaur dan berinteraksi dengan kelompook baru. Kemampuan beradaptasi membuat pengungsi mempunyai rasa tanggung jawab dan hubungan persahabatan yang baik dengan kelompok barunya sebagai sesama pengungsi, sehingga bisa mengurangi tekanan dan trauma akibat dari bencana yang dialaminya. 
Kesebelas adalah adequate emancipation from the group or culture (mempunyai emansipasi yang memadai dari kelompok atau budaya). Pengungsi mampu untuk menilai baik buruknya suatu tindakan tanpa adanya pengaruh dari orang lain. Pengungis juga mampu menghargai perbedaan dengan kebudayaan orang lain. Hal ini menjadi penting bagi pengungsi agar tidak mudah terjadi konflik dengan sesama pengungsi yang memiliki nilai dan budaya yang berbeda.

Berdasarkan analisa terhadap kondisi pengungsi dikatikan dengan dimensi kesehatan mental tersebut, maka berbagai macam dimensi kesehatan mental tersebut harus diusahakan untuk dapat dipenuhi agar para pengungsi dapat terhindar dari gangguan kesehatan mental yang sangat mungkin untuk terjadi.

Pemenuhan kebutuhan dan kapasitas para pengungsi terkait kesebelas dimensi kesehatan mental yang diungkapkan oleh Maslow dan Mittlemenn (dalam Notosoedirjo \& Latipun, 2005) tersebut dinilai mampu untuk menekan tingkat stress dan trauma dari pengungsi. Untuk itu, diperlukan bantuan dan dukungan dari para praktisi yang bergeran di bidang pengananan pengungsi dan yang berkecimpung dalam penanganan kesehatan mental. Salah satunya adalah profesi pekerjaan sosial yang dapat turut berperan serta menangani para pengungsi agar terhindar dari gangguan kesehatan mental.

Adapun peran yang dapat dilakukan oleh pekerja sosial dalam hal ini adalah:

\section{Advokasi}

Dalam melakukan advokasi, pekerja sosial dapat melakukan upaya perlindungan dan mewakili kepentingan para pengungsi dalam melakukan koordinasi dengan pihakpihak terkait (terutama dengan pihak Pemerintah) agar hak-hak dari para pengungsi dan kebutuhan dasar mereka dapat terpenuhi dengan layak. Selain itu Pekerja sosial juga dapat mengadvokasi agar para pengungsi dapat tetap memperoleh kehidupan yang layak yang diberikan oleh negara dan pihak-pihal lainnya secara lebih luas.

\section{Fasilitator}

Sebagai fasilitator, pekerja sosial dapat membantu para pengungsi dalam berhubungan dengan sistem sumber yang berkompeten guna memenuhi kebutuhan mereka. Sistem sumber yang dimaksud adalah sumber terhadap pemenuhan kebutuhan hidup, mulai dari kebutuhan pangan, sandang dan pangan. Selaian itu juga sistem sumber untuk akses pekerjaan dan pendidikan serta sistem sumber terkait bantuan lainnya. Terutama yang bisa dilakukan oleh lembaga pemerintah dan lembaga non pemerintah.

3. Membentuk Kelompok-kelompok Bantu Diri (Self Help).

Pembentukan kelompok ini dimaksudkan agar pengungsi dapat saling mendukung di antara mereka sendiri dalam menghadapi situasi dan kondisi kehidupan di dalam kamp penampungan, memikirkan dan merencanakan alternatif-alternatif pemecahan masalah dan langkahlangkah yang dapat ditempuh apabila bencana terjadi kembali dan menginventarisir berbagai macam kebutuhan maupun sistem sumber yang diharapkan dapat membantu mereka.

4. Partisipasi

Pekerja sosial dapat melibatkan para pengungsi dalam kegiatan-kegiatan yang dilaksanakan di kamp pengungsian, seperti dapur umum, membangun fasilitas umum atau perbaikan sanitasi lingkungan dan menciptakan beberapa kegiatan baru, misalnya dengan menyelenggarakan latihan keterampilan yang sederhana, melibatkan para orang tua untuk ikut mendirikan dan mengajar di sekolah tenda dan sebagainya. Kegiatan ini bertujuan agar pengungsi dapat mengalihkan berbagai macam perasaan negatifnya seperti rasa cemas, rasa takut dan lain sebagainya menjadi 


\begin{tabular}{|c|c|c|c|c|}
\hline $\begin{array}{c}\text { Jurnal Penelitian \& } \\
\text { PPM }\end{array}$ & ISSN: 2442-448X & Vol 5, No: 1 & Hal: $1-110$ & April 2018 \\
\hline
\end{tabular}

perasaan yang lebih positif dengan mengikuti berbagai macam kegiatan yang sifatnya gotong royong dan konstruktif.

Selain pekerja sosial dapat bekerja bersama pengungsi dan bidang kesehatan mental secara langsung, pekerja sosial pun dapat bergabung ke dalam organisasi pelayanan sosial baik di tangkat lokal, nasional, regional maupun internasional. Ketika pekerja sosial bergabung ke dalam organisasi pelayann sosial, maka pekerja sosial bisa bergerak secara lebih luas. Misalnya saja saat bergerak dalam organisasi pelayanan sosial di bidang pengungsi seperti UNHCR, pekerja sosial dapat membuat dan mengintervensi kebijakan-kebijakan negara terkait dengan pengungsi dan kesehatan mental. Saat pekerja sosial bergerak di bidang kesehatan seperti WHO, pekerja sosial bisa mengadvokasi bagaimana WHO bisa mentreatment dan melindungi kesehatan mental para pengungsi.

\section{Simpulan}

Pengungsi yang diakibatkan dari bencana mempunyai banyak kerentanan untuk dapat secara sadar menerima dampak negatif dari bencana tersebut. Hal yang paling rentan terjadi terhadap para pengungsi bahkan dapat berdampak panjang adalah terjadinya gangguan kesehatan mental pada diri pengungsi. Kesehatan mental yang mungkin terjadi akibat dari terjadinya bencana adalah seperti anxiety, depresi hingga PTSD (Post Traumatic Stress Disorder).

Dengan demikian, assessment dan identifikasi terhadap kesehatan mental dari para pengungsi sangat perlu untuk dilakukan, salah satunya dengan menggunakan dimensidimensi kesehatan mental yang diungkapkan oleh Maslow dan Mittlemenn (dalam Notosoedirjo \& Latipun, 2005) yang menekankan pemberian dukungan emosi dan rasa aman bagi para pengungsi sebagai dasar pondasi utama di dalam kesehatan mental.
Profesi pekerjaan sosial pun berperan penting dalam upaya penanganan pengungsi dan penganganan gangguang kesehatan mental mereka. Beberapa peran yang dapat dilakukan oleh pekerja sosial adalah berperan sebagai advokator, sebagai fasilitator, membentuk kelompok-kelompok bantu diri (self-help) dan menggugah partisipasi dari para pengungsi agar ikut serta dalam melakukan kegiatankegiatan yang telah digagas oleh pekerja sosial. Selain itu, pekerja sosial pun dapat bergabung dengan organisasi sosial di tingkat local, nasional, regional maupun internasional untuk menangani permasalahan yang dihadapi oleh pengungsi dan gangguan kesehatan mental yang dialami oleh para pengungsi.

\section{Daftar Pustaka}

Budhi Wibawa, Santoso T. Raharjo, Meilanny Budiarti S. (2010). Dasar-Dasar Pekerjaan Sosial. Bandung. Widya Padjadjaran.

Jesuit Refugee Service Indonesia. (2013). Pengungsi dan Pencari Suaka di Indonesia. Yogyakarta

Konvensi PBB tentang Kedudukan Pengungsi. (1951)

Kusumo, B. E. (2009). Kesehatan Mental di Aceh Pasca Tsunami. Jurnal Sosiologi Dilema, 54-58

Notosoedirdjo \& Latipun. (2005). Kesehatan Mental, Konsep dan Penerapan. Jakarta: EGC

Panos Vontanis. (2007). Mental Health Interventions and Services for Vulnerable Children and Young People, Jessica Kingsley Publisher

Raharjo, ST (ed). (2016). Kerentanan dan Disabilitas, Kumpulan Tulisan. Bandung: Unpad Press.

Raharjo, ST .(2015). Pekerjaan Sosial Generalis, Pengantar Bekerja Bersama Organisasi dan Komunitas. Bandung: Unpad Press. 


\begin{tabular}{|c|c|c|c|c|}
\hline $\begin{array}{c}\text { Jurnal Penelitian \& } \\
\text { PPM }\end{array}$ & ISSN: 2442-448X & Vol 5, No: 1 & Hal: $1-110$ & April 2018 \\
\hline
\end{tabular}

Wibhawa, B., Raharjo, ST., \& Santoso, MB. 2010. Dasar Dasar Pekerjaan Sosial. Widya Padjadjaran: Bandung
Yusuf, Syamsu. (2004). Mental Hygiene Perkembangan Kesehatan Mental dalam Kajian Psikologi dan Agama. Bandung: Pustaka Bani Quraisy 